\title{
A cross-sectional study assessing the association between online ratings and clinical quality of care measures for US hospitals: results from an observational study
}

Martin Emmert ${ }^{1,2^{*}}$, Nina Meszmer ${ }^{2,3}$ and Mark Schlesinger ${ }^{4}$

\begin{abstract}
Background: Little is known about the usefulness of online ratings when searching for a hospital. We therefore assess the association between quantitative and qualitative online ratings for US hospitals and clinical quality of care measures.

Methods: First, we collected a stratified random sample of 1000 quantitative and qualitative online ratings for hospitals from the website RateMDs. We used an integrated iterative approach to develop a categorization scheme to capture both the topics and sentiment in the narrative comments. Next, we matched the online ratings with hospital-level quality measures published by the Centers for Medicare and Medicaid Services. Regarding nominally scaled measures, we checked for differences in the distribution among the online rating categories. For metrically scaled measures, we applied the Spearman rank coefficient of correlation.

Results: Thirteen of the twenty-nine quality of care measures were significantly associated with the quantitative online ratings (Spearman $p= \pm 0.143, p<0.05$ for all). Thereof, eight associations indicated better clinical outcomes for better online ratings. Seven of the twenty-nine clinical measures were significantly associated with the sentiment of patient narratives ( $p= \pm 0.114, p<0.05$ for all), whereof four associations indicated worse clinical outcomes in more favorable narrative comments.

Conclusions: There seems to be some association between quantitative online ratings and clinical performance measures. However, the relatively weak strength and inconsistency of the direction of the association as well as the lack of association with several other clinical measures may not enable the drawing of strong conclusions. Narrative comments also seem to have limited potential to reflect the clinical quality of care in its current form. Thus, online ratings are of limited usefulness in guiding patients towards high-performing hospitals from a clinical point of view. Nevertheless, patients might prefer different aspects of care when choosing a hospital.
\end{abstract}

Keywords: Online ratings, Public reporting, Patient satisfaction, Patient narratives, Quality of care

\footnotetext{
*Correspondence: martin.emmert@yale.edu; martin.emmert@fau.de

'2014-15 Harkness \& Robert Bosch Fellow in Healthcare Policy and Practice;

Department of Health Policy and Management, Yale University, School of

Public Health, 47 College Street, New Haven, CT 06520, USA

${ }^{2}$ Friedrich-Alexander-University Erlangen-Nuremberg, School of Business and

Economics, Institute of Management (IFM), Lange Gasse 20, 90403

Nuremberg, Germany

Full list of author information is available at the end of the article
} 


\section{Background}

Online rating websites have become a popular tool for increasing transparency regarding the quality of care of health care providers [1-3]. Besides a scaled survey, several rating websites (e.g., Yelp, FindTheBest - HealthGrove, RateMDs) have implemented a narrative commentary field [4] so that patients can report on their experience in their own words. So far, literature has shown the increasing popularity of such websites when it comes to the number of ratings $[2,5,6]$, the traffic rank [5, 7], and the awareness of the population [8]. What we further know is that a large proportion of quantitative online ratings [2, 5, 9-13] and patients' narratives are positive $[1,3,14]$.

However, literature has also raised concerns regarding the usage of online rating websites. First, the derived ratings are not risk adjusted and thus do not seem to be appropriate to represent a provider's quality of care [15]. In addition, the presented results are vulnerable to fraud since ratings are totally or partly anonymous on some rating websites [16] (However, it also has to be mentioned that certain rating websites have implemented different measures to deal with the problems of anonymous ratings; e.g., the Dutch patient rating website Zorgkaart or the German rating website jameda). It is also important to mention that people providing feedback on health care via social media are presumably not always representative of the patient population, which might limit the usefulness for certain patient groups [16, 17]. Studies have further shown that national hospital rating systems in the US may generate confusion rather than clarity as they share few common scores $[18,19]$. Finally, since the ratings are often based on only a few reviews and are mostly positive $[5,6,11]$, the usefulness of the ratings for patients might be limited. (However, recent research from the Netherlands has demonstrated that information from social media which integrates the patient's perspective can be important for health care inspectorates, especially for its enforcement by riskbased supervision of elderly care [20].) In this context, one study recently showed that the overrepresentation of positive comments in online reviews might enable ineffective treatments to maintain a good reputation [21]. Applying this finding to the health care provider rating context, it means that low-performing providers may be likely to have positive ratings, which could lead to suboptimal provider choices.

It thus remains questionable whether patients should rely on online ratings when choosing a provider [15]. In cases where the ratings are strongly correlated with clinical quality of care measures, it might be easier for patients to single out the best performers, which would increase the usefulness of the ratings. In contrast, if the ratings are uncorrelated or even negatively correlated with clinical performance measures, the choice becomes harder since consumers must strike trade-offs among attractive attributes [22]. To date, there is little evidence regarding the association between online ratings and clinical performance measures for hospitals in the US. To the best of our knowledge, there is only one study available evaluating the association between quantitative online ratings and hospital performance metrics [23]. (Two similar studies are available but focus on the association between online ratings and performance metrics based on the individual provider level $[24,25])$. Furthermore, no study refers to the association between narrative comments and clinical performance measures. In this context, the present study aims at adding further knowledge on whether both quantitative and qualitative patient satisfaction results displayed on US hospital rating websites demonstrate an association with clinical performance measures.

\section{Methods}

This study was designed as a cross-sectional study by analyzing the association between online derived patient ratings and clinical measures for US hospitals. Thereof, we collected a random sample of 1000 online ratings for US hospitals from RateMDs (04/2015). The website RateMDs uses a five-point scaled rating system of star rating scores and narrative comments to ask patients about their overall impressions about hospitals. Consequently, the collected data contains quantitative ratings and narrative comments. Since the aim of this study was to assess the differences between the five rating scores, we stratified the sample by rating score and collected 200 ratings of each rating score. As a maximum, we collected a total of 20 ratings for each state with an equally distribution of rating scores. Thereof, we collected the first ten ratings of each state starting with the best hospital and the remaining ten ratings were collected by starting with the worst hospital. In case not enough ratings were available within one state, we filled up the missing data with hospital ratings from other states.

In a next step, we used qualitative content analysis to determine the topics discussed in the narrative comments [26, 27] by using previous evidence [28]. We therefore conducted a search procedure in Medline (via PubMed) to identify previously published categorization schemes for narrative comments related to hospital ratings $(10 / 2014$; not presented here in detail). The identified schemes served as a starting point and were further extended in an iterative process. Our developed categorization framework aimed to capture both the topics mentioned within the narrative comments and the sentiment. We therefore applied both deductive and inductive steps-i.e. new categories were added until a saturation of topics had been reached [28]. The final 
framework was applied during a pre-test of 100 randomly selected narrative comments. Next, the content of each narrative comment was classified according to our final framework with respect to both the topic and the sentiment as positive, neutral, or negative [29]. Two of the authors independently carried out the assessment. The inter-rater agreement between the two raters was assessed using Cohen's kappa coefficient (weighted) and was calculated to be 0.813 ; $95 \mathrm{CI}: 0.796-0.834$ ). We then derived the overall sentiment of each comment as positive, negative, or neutral $[30,31]$, based on the proportion of positive topics in each comment.

The clinical quality measures were derived from the Hospital Compare database published by the Centers for Medicare and Medicaid Services (CMS) [32] and downloaded from Data.Medicare.gov. For our study purpose, we focused on non-disease specific clinical quality measures, since we expected the narrative comments to be non-disease related in most cases. In total, we included 29 quality measures related to healthcare associated infections $(N=4)$, readmissions, complications and deaths $(N=5)$, as well as timely and effective care $(N=20)$. We then assigned the hospital ID included in the CMS dataset to the hospitals in our RateMDs database and matched the two datasets before conducting our analysis.

All statistical analyses were carried out by means of SPSS V22.0 (IBM Corp, Armonk, NY, USA). Descriptive analysis included calculating the mean and standard deviation (SD) for the characteristics of narrative comments as well as rated hospitals. The Kruskal Wallis test was used to determine the differences in non-parametric data between the rating performance groups. Two approaches were used to learn more about the association between the online ratings and clinical measures according to the display on Hospital Compare. First, regarding nominally scaled measures, we checked for differences in the distribution across the scaled survey rating and sentiment categories by using the chi-square test. Second, regarding metrically scaled measures, we applied the Spearman rank coefficient of correlation to measure the association between online ratings and quality of care information; (none of our dependent variables was normally distributed according to the Shapiro-Wilk test; $p<0.001$, data not shown here). The association was calculated by adjusting for hospital type, hospital ownership, and emergency service. We also analyzed the correlation between the lengths of comments and the evaluation results and between the overall patient experience derived from the scaled survey results and the narrative comments. Inter-rater agreement between the two raters was assessed using Cohen's kappa coefficient (weighted). Observed differences were considered statistically significant if $p<.05$ and highly significant if $p<.001$.

\section{Results}

\section{Systematic search procedure and categorization} framework

Our search procedure identified one study which analyzes and categorizes narrative comments derived from online hospital report cards about the hospital experience from the UK and was taken as the initial basis for our categorization framework [33]. Further studies which deal with a slightly different question were also screened to capture comment categories [29-31, 34-36]. Our applied categorization scheme distinguishes between ten main categories: the received care, facilities, wait time, clinicians and staff, communication, costs of care, personal issues, acknowledgements, recommendations for or against using the hospital, and others. (See Additional file 1 for an overview of our final categorization scheme/codebook, a further description of the categories, and examples of positive and negative comments.)

\section{Content and sentiment analysis of the narrative comments}

Table 1 provides an overview of the hospitals $(N=623)$ related to the 1000 analyzed online ratings. Most ratings relate to acute care (98\%) and voluntary non-profit hospitals, and those who provide emergency services (97\%).

As displayed in Table 2, the mean length of the comments was 62.33 words (SD 63.17), wherein positive comments (37.63; SD 37.23) were significantly shorter than neutral (73.40; SD 73.03) or negative (74.34; SD $69.02)$ comments $(p<0.001)$. In total, 3453 topics were mentioned within the comments, whereby negative descriptions $(62.4 \%)$ were more likely than positive (34.5\%) or neutral (3.2\%) descriptions. We classified $32.2 \%$ of all comments as overall positive, $6.0 \%$ as neutral and $61.8 \%$ as negative (inter-rater agreement: 0.793; 95 CI: 0.7630.824).

Regarding the twenty most frequently mentioned topics (see Table 3), most comments contained a description of the general impression of the patient's hospital stay (583 out of 1000). Therein, comments were more likely to be negative $(54.5 \%)$ than positive $(41.0 \%)$. As demonstrated, the distribution of the topics varies among the scaled survey rating results. For example, patients were most likely to report on unintended consequences in one or two star ratings $(33.7 \%$ and $30.1 \%$, respectively), but not in very positive ratings.

\section{Association between scaled survey ratings and quality of care measures}

Table 4 shows the distribution of the nominally scaled clinical performance results across the scaled survey rating categories on RateMDs. Therein, the probability of choosing a high-performing hospital is greater in five star ratings compared with one star ratings in only two 
Table 1 Characteristics of all hospitals in our sample compared with all US hospitals

\begin{tabular}{|c|c|c|c|}
\hline Criteria & Characteristics & $\begin{array}{l}\text { Sample Hospitals } \\
(N=623 ; \text { in \%) }\end{array}$ & $\begin{array}{l}\text { US Hospitals }^{a} \\
(N=4861 \text {; in \%) }\end{array}$ \\
\hline \multirow[t]{3}{*}{ Hospital Type } & $\begin{array}{l}\text { Critical Access } \\
\text { Hospitals }\end{array}$ & 2.0 & 25.8 \\
\hline & $\begin{array}{l}\text { Acute Care } \\
\text { Hospitals }\end{array}$ & 98.0 & 73.7 \\
\hline & Childrens & 0.0 & 0.5 \\
\hline \multirow[t]{5}{*}{$\begin{array}{l}\text { Hospital } \\
\text { Ownership }\end{array}$} & $\begin{array}{l}\text { Government } \\
\text { Hospitals }\end{array}$ & 14.6 & 25.5 \\
\hline & $\begin{array}{l}\text { Hospitals owned } \\
\text { by physicians }\end{array}$ & 0.9 & 1.1 \\
\hline & $\begin{array}{l}\text { Proprietary } \\
\text { Hospitals }\end{array}$ & 17.8 & 16.2 \\
\hline & $\begin{array}{l}\text { Voluntary non- } \\
\text { profit Hospitals }\end{array}$ & 66.7 & 57.2 \\
\hline & Tribal & 0.0 & 0.0 \\
\hline \multirow{2}{*}{$\begin{array}{l}\text { Emergency } \\
\text { Service }\end{array}$} & Yes & 96.8 & 92.1 \\
\hline & No & 3.2 & 7.9 \\
\hline \multirow{3}{*}{$\begin{array}{l}\text { Ability to receive } \\
\text { lab results } \\
\text { electronically }\end{array}$} & Yes & 81.1 & 67.4 \\
\hline & No & 14.3 & 20.5 \\
\hline & Not Available & 4.6 & 12.1 \\
\hline \multirow{3}{*}{$\begin{array}{l}\text { Ability to track } \\
\text { patients' lab } \\
\text { results, tests, } \\
\text { and referrals } \\
\text { electronically } \\
\text { between visits }\end{array}$} & Yes & 74.7 & 61.9 \\
\hline & No & 20.6 & 25.6 \\
\hline & Not Available & 4.7 & 12.5 \\
\hline \multirow{3}{*}{$\begin{array}{l}\text { Safe Surgery } \\
\text { Checklist Use }\end{array}$} & Yes & 88.5 & 79.1 \\
\hline & No & 6.9 & 8.9 \\
\hline & Not Available & 4.6 & 12.0 \\
\hline \multirow[t]{4}{*}{$\begin{array}{l}\text { Cardiac } \\
\text { surgery registry }\end{array}$} & $\begin{array}{l}\text { Does not have } \\
\text { a Cardiac Surgery }\end{array}$ & 40.7 & 55.4 \\
\hline & Yes & 52.0 & 22.7 \\
\hline & No & 3.1 & 1.3 \\
\hline & Not Available & 4.2 & 20.7 \\
\hline \multirow{3}{*}{$\begin{array}{l}\text { General } \\
\text { surgery registry }\end{array}$} & Yes & 28.9 & 13.9 \\
\hline & No & 66.9 & 65.5 \\
\hline & Not Available & 4.2 & 20.7 \\
\hline \multirow{3}{*}{$\begin{array}{l}\text { Nursing care } \\
\text { registry }\end{array}$} & Yes & 63.9 & 35.4 \\
\hline & No & 31.9 & 44.0 \\
\hline & Not Available & 4.2 & 20.7 \\
\hline
\end{tabular}

Table 1 Characteristics of all hospitals in our sample compared with all US hospitals (Continued)

\begin{tabular}{llll}
\hline Criteria & Characteristics & $\begin{array}{l}\text { Sample Hospitals } \\
(N=623 ; \text { in \%) }\end{array}$ & $\begin{array}{l}\text { US Hospitals } \\
(N=4861 ; \text { in \%) }\end{array}$ \\
\hline $\begin{array}{l}\text { Stroke care } \\
\text { registry }\end{array}$ & Yes & 65.1 & 35.9 \\
& No & 30.7 & 43.4 \\
& Not Available & 4.2 & 20.7 \\
\hline
\end{tabular}

${ }^{a}$ Based on the Hospital Compare database $(\mathrm{N}=4861)$

of the nine measures (i.e., central line-associated bloodstream infections, rate of readmission after discharge from hospital).

After adjusting for hospital characteristics, we detected significant associations between the metrically scaled quality measures and the scaled online ratings for thirteen of the twenty-nine quality of care measures (Table 5). Regarding healthcare associated infections, central lineassociated bloodstream infections were negatively associated with the rating results on RateMDs; the higher the number of stars of the rating (i.e., the better the rating), the lower the infection scores $(\rho=-0.087, p<0.05)$. Further significant associations were measured between the scaled online ratings and two readmission, complications and deaths measures. Interestingly, the results for the measure collapsed lung due to medical treatment were positively associated with the ratings $(\rho=0.080, p<0.05)$, whereas lower readmission rates after discharge from hospital were negatively associated with the online ratings $(\rho=-0.070, p<0.05)$. Finally, the associations between online ratings and timely and effective care measures proved to be significant in ten of the twenty measures $(\rho= \pm 0.143, p<0.05$ for all), wherein six significant associations indicate better clinical outcomes for higher star ratings. In sum, eight out of the thirteen determined significant associations indicate better clinical outcomes for higher star ratings.

\section{Association between narrative comments and quality of care measures}

When choosing a hospital based on the sentiment of the narrative comments, the probability of selecting a highperforming hospital is greater in five of the nine measures (see Table 4). However, we could also detect (in most cases marginally) higher percentages for selecting a low-performing hospital for narrative comments with a positive sentiment in eight of the nine measures. After adjusting for hospital characteristics, seven of the twenty-nine metrically scaled clinical measures were significantly associated with the sentiment of the patient narratives (Table 5). In line with the results above, narrative comments are negatively associated with one readmission, complication and death measure (collapsed lung due to medical treatment; $\rho=0.078, p<0.05$ ), 
Table 2 Descriptive analysis of the narrative comments and the sentiment

\begin{tabular}{|c|c|c|c|c|c|c|c|c|c|c|c|c|c|}
\hline \multirow{2}{*}{$\begin{array}{l}\text { Overall rating } \\
\text { result (scaled- } \\
\text { survey ratings) }\end{array}$} & \multicolumn{2}{|c|}{$\begin{array}{l}\text { Length of comments } \\
\text { (in words) }\end{array}$} & \multicolumn{3}{|c|}{ Number of topics mentioned } & \multicolumn{4}{|c|}{ Sentiment of topics ( $N=3453$; in \%) } & \multicolumn{4}{|c|}{$\begin{array}{l}\text { Overall sentiment of comments } \\
(N=1000 \text {; in \%) }\end{array}$} \\
\hline & Mean \pm SD & $p^{1}$ & Total & Mean \pm SD & $p^{1}$ & Positive & Neutral & Negative & $p^{2}$ & Positive & Neutral & Negative & $p^{2}$ \\
\hline One star & $73.02 \pm 78.04$ & $<.001$ & 697 & $3.48 \pm 2.15$ & .209 & 1.6 & 1.9 & 96.6 & $<.001$ & 1.0 & 1.0 & 98.0 & $<.001$ \\
\hline Two stars & $79.05 \pm 69.51$ & & 735 & $3.68 \pm 1.17$ & & 4.1 & 1.4 & 94.6 & & 1.5 & 1.0 & 97.5 & \\
\hline Three stars & $72.62 \pm 65.17$ & & 700 & $3.50 \pm 2.05$ & & 14.6 & 6.3 & 79.1 & & 2.5 & 12.5 & 85.0 & \\
\hline Four stars & $48.53 \pm 45.09$ & & 653 & $3.27 \pm 2.11$ & & 61.1 & 6.1 & 32.8 & & 57.5 & 15.0 & 27.5 & \\
\hline Five stars & $38.45 \pm 39.54$ & & 668 & $3.34 \pm 2.10$ & & 97.2 & 0.3 & 2.5 & & 98.5 & 0.5 & 1.0 & \\
\hline Overall & $62.33 \pm 63.17$ & & 3453 & $3.45 \pm 2.10$ & & 34.5 & 3.2 & 62.4 & & 32.2 & 6.0 & 61.8 & \\
\hline
\end{tabular}

${ }^{\mathrm{a} A}$ higher number of stars indicate a better overall rating; Note: each rating result group contained 200 analysed narrative comments

${ }^{1}$ Kruskal Wallis test

${ }^{2}$ Chi-square test

indicating lower clinical performance scores in narrative comments with a positive sentiment. The significant associations between the comments and timely and effective care measures were determined to be inconsistent. Three associations indicate better clinical outcomes in more favorable narrative comments: (1) average time patients spent in the emergency department before being sent home $(\rho=-0.085, p<0.05)$; (2) average time patients spent in the emergency department before they were seen by a health care professional $(\rho=-0.113$, $p<0.001$ ); and (3) patients who got treatment to prevent blood clots on the day of or day after hospital admission or surgery $(\rho=0.070, p<0.05)$. In contrast, three quality measures are negatively associated with the sentiment of the comments: (1) patients having surgery who were actively warmed in the operating room or whose body temperature was near normal by the end of surgery $(\rho=-0.079, p<0.05)$; (2) surgery patients whose preventive antibiotics were stopped at the right time (within $24 \mathrm{~h}$ after surgery) $(\rho=-0.098$, $p<0.05$ ); and (3) patients who got treatment at the right time (within $24 \mathrm{~h}$ before or after their surgery) to help prevent blood clots after certain types of surgery $(\rho=-0.114, p<0.05)$. Finally, we determined a

Table 3 Results from the sentiment analysis and the distribution among the five quantitative rating categories

\begin{tabular}{|c|c|c|c|c|c|c|c|c|c|c|}
\hline \multirow[t]{2}{*}{$\mathrm{Nr}$} & \multirow[t]{2}{*}{ Category } & \multirow[t]{2}{*}{$\mathrm{N}$} & \multicolumn{3}{|c|}{ Sentiment analysis of comments } & \multicolumn{5}{|c|}{ Quantitative RateMDs Overall Ratings } \\
\hline & & & Positive & Neutral & Negative & One star & Two stars & Three stars & Four stars & Five stars \\
\hline 1 & General Impression of the care received & 583 & $41.0 \%$ & $4.5 \%$ & $54.5 \%$ & $21.3 \%$ & $19.2 \%$ & $16.0 \%$ & $19.4 \%$ & $24.2 \%$ \\
\hline 2 & Demeanor Staff/Overall & 248 & $46.8 \%$ & $2.0 \%$ & $51.2 \%$ & $20.6 \%$ & $17.7 \%$ & $16.1 \%$ & $18.5 \%$ & $27.0 \%$ \\
\hline 3 & Demeanor Nursing & 168 & $36.9 \%$ & $3.6 \%$ & $59.5 \%$ & $21.4 \%$ & $21.4 \%$ & $19.6 \%$ & $19.6 \%$ & $17.9 \%$ \\
\hline 4 & Recommendation & 152 & $21.7 \%$ & $0.7 \%$ & $77.6 \%$ & $36.2 \%$ & $23.7 \%$ & $17.8 \%$ & $5.9 \%$ & $16.4 \%$ \\
\hline 5 & Cleanliness of the facility & 143 & $37.8 \%$ & $2.8 \%$ & $59.4 \%$ & $32.2 \%$ & $16.1 \%$ & $14.0 \%$ & $16.8 \%$ & $21.0 \%$ \\
\hline 6 & Demeanor Physicians & 130 & $33.8 \%$ & $1.5 \%$ & $64.6 \%$ & $21.5 \%$ & $20.8 \%$ & $22.3 \%$ & $19.2 \%$ & $16.2 \%$ \\
\hline 7 & Wait time within hospital & 127 & $7.1 \%$ & $0.8 \%$ & $92.1 \%$ & $16.5 \%$ & $33.9 \%$ & $26.0 \%$ & $16.5 \%$ & $7.1 \%$ \\
\hline 8 & Effectiveness of the hospital care & 124 & $27.4 \%$ & $3.2 \%$ & $69.4 \%$ & $22.6 \%$ & $20.2 \%$ & $21.0 \%$ & $17.7 \%$ & $18.5 \%$ \\
\hline 9 & General Physicians & 122 & $63.9 \%$ & $7.4 \%$ & $28.7 \%$ & $19.7 \%$ & $9.8 \%$ & $17.2 \%$ & $24.6 \%$ & $28.7 \%$ \\
\hline 10 & General Nursing & 105 & $65.7 \%$ & $12.4 \%$ & $21.9 \%$ & $7.6 \%$ & $12.4 \%$ & $20.0 \%$ & $38.1 \%$ & $21.9 \%$ \\
\hline 11 & General Staff/Overall & 102 & $67.6 \%$ & $3.9 \%$ & $28.4 \%$ & $7.8 \%$ & $8.8 \%$ & $10.8 \%$ & $28.4 \%$ & $44.1 \%$ \\
\hline 12 & Effectiveness of the staff care & 95 & $15.8 \%$ & $0.0 \%$ & $84.2 \%$ & $25.3 \%$ & $31.6 \%$ & $18.9 \%$ & $12.6 \%$ & $11.6 \%$ \\
\hline 13 & Staff prompt Staff/Overall & 89 & $40.4 \%$ & $1.1 \%$ & $58.4 \%$ & $10.1 \%$ & $25.8 \%$ & $20.2 \%$ & $19.1 \%$ & $24.7 \%$ \\
\hline 14 & Service & 85 & $43.5 \%$ & $2.4 \%$ & $54.1 \%$ & $10.6 \%$ & $23.5 \%$ & $18.8 \%$ & $20.0 \%$ & $27.1 \%$ \\
\hline 15 & Unintended consequences & 83 & $0.0 \%$ & $0.0 \%$ & $100.0 \%$ & $33.7 \%$ & $30.1 \%$ & $26.5 \%$ & $9.6 \%$ & $0.0 \%$ \\
\hline 16 & Facility Building & 76 & $46.1 \%$ & $7.9 \%$ & $46.1 \%$ & $14.5 \%$ & $11.8 \%$ & $23.7 \%$ & $28.9 \%$ & $21.1 \%$ \\
\hline 17 & Care Effectiveness Physicians & 73 & $12.3 \%$ & $1.4 \%$ & $86.3 \%$ & $30.1 \%$ & $26.0 \%$ & $24.7 \%$ & $13.7 \%$ & $5.5 \%$ \\
\hline 18 & Amount of Costs & 57 & $1.8 \%$ & $3.5 \%$ & $94.7 \%$ & $17.5 \%$ & $26.3 \%$ & $36.8 \%$ & $17.5 \%$ & $1.8 \%$ \\
\hline 19 & Coordination of Care & 54 & $16.7 \%$ & $1.9 \%$ & $81.5 \%$ & $16.7 \%$ & $38.9 \%$ & $18.5 \%$ & $11.1 \%$ & $14.8 \%$ \\
\hline 20 & Food & 53 & $45.3 \%$ & $3.8 \%$ & $50.9 \%$ & $13.2 \%$ & $9.4 \%$ & $15.1 \%$ & $32.1 \%$ & $30.2 \%$ \\
\hline
\end{tabular}


Table 4 Distribution of the nominally scaled clinical performance results according to the online ratings on RateMDs

\begin{tabular}{|c|c|c|c|c|c|c|c|c|c|c|}
\hline & \multicolumn{6}{|c|}{ Scaled survey ratings } & \multicolumn{4}{|c|}{ Narrative comment sentiment } \\
\hline & One star & Two stars & Three stars & Four stars & Five stars & $p$ & Positive & Neutral & Negative & $p$ \\
\hline \multicolumn{11}{|l|}{ Healthcare Associated Infections } \\
\hline \multicolumn{11}{|c|}{ Central Line-Associated Bloodstream Infection (CLABSI) } \\
\hline Better than the US national benchmark & $20.9 \%$ & $24.5 \%$ & $22.7 \%$ & $22.1 \%$ & $25.7 \%$ & $* *$ & $23.1 \%$ & $12.3 \%$ & $25.5 \%$ & ** \\
\hline No different than the US national benchmark & $49.4 \%$ & $37.2 \%$ & $40.3 \%$ & $39.7 \%$ & $20.4 \%$ & & $42.3 \%$ & $39.5 \%$ & $26.7 \%$ & \\
\hline Worse than the US national benchmark & $0.6 \%$ & $0.0 \%$ & $1.1 \%$ & $0.0 \%$ & $0.0 \%$ & & $0.4 \%$ & $1.2 \%$ & $0.0 \%$ & \\
\hline Number of cases too small & $1.2 \%$ & $0.5 \%$ & $3.3 \%$ & $1.0 \%$ & $6.1 \%$ & & $2.0 \%$ & $1.2 \%$ & $4.1 \%$ & \\
\hline Not available & $27.9 \%$ & $37.8 \%$ & $32.6 \%$ & $37.2 \%$ & $47.8 \%$ & & $32.2 \%$ & $45.7 \%$ & $43.8 \%$ & \\
\hline \multicolumn{11}{|l|}{ Catheter-Associated Urinary Tract Infections (CAUTI) } \\
\hline Better than the US national benchmark & $8.1 \%$ & $8.2 \%$ & $9.9 \%$ & $8.1 \%$ & $4.8 \%$ & $* *$ & $9.1 \%$ & $7.4 \%$ & $5.8 \%$ & ** \\
\hline No different than the US national benchmark & $49.4 \%$ & $40.8 \%$ & $45.9 \%$ & $40.6 \%$ & $30.6 \%$ & & $44.9 \%$ & $35.8 \%$ & $35.4 \%$ & \\
\hline Worse than the US national benchmark & $15.7 \%$ & $16.3 \%$ & $12.2 \%$ & $14.7 \%$ & $11.8 \%$ & & $15.1 \%$ & $12.3 \%$ & $12.2 \%$ & \\
\hline Number of cases too small & $1.2 \%$ & $0.5 \%$ & $3.3 \%$ & $1.0 \%$ & $6.1 \%$ & & $2.0 \%$ & $1.2 \%$ & $4.1 \%$ & \\
\hline Not available & $25.6 \%$ & $34.2 \%$ & $28.7 \%$ & $35.5 \%$ & $46.7 \%$ & & $28.8 \%$ & $43.2 \%$ & $42.6 \%$ & \\
\hline \multicolumn{11}{|c|}{ MRSA blood Laboratory-identified Events (bloodstream infections) } \\
\hline Better than the US national benchmark & $4.1 \%$ & $2.6 \%$ & $1.7 \%$ & $1.0 \%$ & $1.3 \%$ & ** & $2.9 \%$ & $1.3 \%$ & $1.2 \%$ & * \\
\hline No different than the US national benchmark & $53.5 \%$ & $50.3 \%$ & $48.6 \%$ & $52.5 \%$ & $41.0 \%$ & & $50.2 \%$ & $48.8 \%$ & $45.9 \%$ & \\
\hline Worse than the US national benchmark & $3.5 \%$ & $2.6 \%$ & $7.2 \%$ & $3.0 \%$ & $0.9 \%$ & & $4.7 \%$ & $1.3 \%$ & $1.7 \%$ & \\
\hline Number of cases too small & $1.7 \%$ & $0.0 \%$ & $3.3 \%$ & $1.0 \%$ & $5.2 \%$ & & $2.2 \%$ & $0.0 \%$ & $3.5 \%$ & \\
\hline Not available & $37.2 \%$ & $44.6 \%$ & $39.2 \%$ & $42.4 \%$ & $51.5 \%$ & & $40.0 \%$ & $48.8 \%$ & $47.7 \%$ & \\
\hline \multicolumn{11}{|c|}{ Clostridium difficile (C.diff.) Laboratory identified Events } \\
\hline Better than the US national benchmark & $19.8 \%$ & $16.4 \%$ & $17.7 \%$ & $13.2 \%$ & $14.4 \%$ & $* *$ & $17.5 \%$ & $13.8 \%$ & $14.2 \%$ & ** \\
\hline No different than the US national benchmark & $42.4 \%$ & $48.2 \%$ & $56.9 \%$ & $54.3 \%$ & $42.4 \%$ & & $52.2 \%$ & $56.3 \%$ & $41.0 \%$ & \\
\hline Worse than the US national benchmark & $15.7 \%$ & $7.7 \%$ & $6.6 \%$ & $11.7 \%$ & $7.0 \%$ & & $10.2 \%$ & $6.3 \%$ & $9.3 \%$ & \\
\hline Number of cases too small & $1.7 \%$ & $0.0 \%$ & $3.3 \%$ & $1.0 \%$ & $5.2 \%$ & & $2.2 \%$ & $0.0 \%$ & $3.5 \%$ & \\
\hline Not available & $20.3 \%$ & $27.7 \%$ & $15.5 \%$ & $19.8 \%$ & $31.0 \%$ & & $18.0 \%$ & $23.8 \%$ & $32.0 \%$ & \\
\hline \multicolumn{11}{|l|}{ Readmissions Complications and Deaths } \\
\hline \multicolumn{11}{|l|}{ Serious blood clots after surgery } \\
\hline Better than the US national benchmark & $6.4 \%$ & $7.7 \%$ & $6.1 \%$ & $3.5 \%$ & $5.2 \%$ & * & $6.9 \%$ & $3.8 \%$ & $4.1 \%$ & \\
\hline No different than the US national benchmark & $62.6 \%$ & $52.6 \%$ & $60.6 \%$ & $61.1 \%$ & $47.4 \%$ & & $58.3 \%$ & $55.0 \%$ & $53.3 \%$ & \\
\hline Worse than the US national benchmark & $7.6 \%$ & $10.7 \%$ & $8.9 \%$ & $8.6 \%$ & $8.7 \%$ & & $9.5 \%$ & $7.5 \%$ & $8.7 \%$ & \\
\hline Number of cases too small & $1.2 \%$ & $0.0 \%$ & $3.9 \%$ & $1.0 \%$ & $5.7 \%$ & & $2.0 \%$ & $1.3 \%$ & $3.8 \%$ & \\
\hline Not available & $22.2 \%$ & $29.1 \%$ & $20.6 \%$ & $25.8 \%$ & $33.0 \%$ & & $23.3 \%$ & $32.5 \%$ & $30.1 \%$ & \\
\hline \multicolumn{11}{|l|}{ Accidental cuts and tears from medical treatment } \\
\hline Better than the US national benchmark & $4.1 \%$ & $3.1 \%$ & $2.8 \%$ & $4.5 \%$ & $3.9 \%$ & * & $3.3 \%$ & $2.5 \%$ & $4.7 \%$ & \\
\hline No different than the US national benchmark & $65.1 \%$ & $60.5 \%$ & $66.7 \%$ & $62.6 \%$ & $48.7 \%$ & & $63.9 \%$ & $58.8 \%$ & $53.8 \%$ & \\
\hline Worse than the US national benchmark & $7.6 \%$ & $7.2 \%$ & $6.7 \%$ & $6.1 \%$ & $7.8 \%$ & & $7.3 \%$ & $6.3 \%$ & $7.0 \%$ & \\
\hline Number of cases too small & $1.2 \%$ & $0.0 \%$ & $3.9 \%$ & $1.0 \%$ & $5.2 \%$ & & $2.2 \%$ & $0.0 \%$ & $3.5 \%$ & \\
\hline Not available & $22.1 \%$ & $29.2 \%$ & $20.0 \%$ & $25.8 \%$ & $34.3 \%$ & & $23.3 \%$ & $32.5 \%$ & $31.1 \%$ & \\
\hline \multicolumn{11}{|l|}{ Collapsed lung due to medical treatment } \\
\hline Better than the US national benchmark & $0.6 \%$ & $1.0 \%$ & $0.6 \%$ & $0.5 \%$ & $0.4 \%$ & * & $0.9 \%$ & $1.3 \%$ & $0.3 \%$ & \\
\hline No different than the US national benchmark & $74.3 \%$ & $66.3 \%$ & $75.0 \%$ & $71.6 \%$ & $59.1 \%$ & & $71.8 \%$ & $65.0 \%$ & $64.2 \%$ & \\
\hline Worse than the US national benchmark & $1.8 \%$ & $3.6 \%$ & $1.1 \%$ & $1.0 \%$ & $2.2 \%$ & & $2.0 \%$ & $1.3 \%$ & $1.7 \%$ & \\
\hline
\end{tabular}


Table 4 Distribution of the nominally scaled clinical performance results according to the online ratings on RateMDs (Continued)

\begin{tabular}{|c|c|c|c|c|c|c|c|c|c|}
\hline & \multicolumn{6}{|c|}{ Scaled survey ratings } & \multicolumn{3}{|c|}{ Narrative comment sentiment } \\
\hline & One star & Two stars & Three stars & Four stars & Five stars & $p$ & Positive & Neutral & Negative $p$ \\
\hline Number of cases too small & $1.2 \%$ & $0.0 \%$ & $3.9 \%$ & $1.0 \%$ & $5.2 \%$ & & $2.2 \%$ & $0.0 \%$ & $3.5 \%$ \\
\hline Not available & $22.2 \%$ & $29.1 \%$ & $19.4 \%$ & $25.9 \%$ & $33.0 \%$ & & $23.1 \%$ & $32.5 \%$ & $30.2 \%$ \\
\hline \multicolumn{10}{|l|}{ Serious complications (PSI-90-SAFETY) } \\
\hline Better than the US national benchmark & $3.5 \%$ & $2.6 \%$ & $3.3 \%$ & $5.1 \%$ & $3.0 \%$ & $*$ & $3.3 \%$ & $1.3 \%$ & $4.1 \%$ \\
\hline No different than the US national benchmark & $66.3 \%$ & $60.2 \%$ & $68.0 \%$ & $61.6 \%$ & $50.4 \%$ & & $64.5 \%$ & $58.8 \%$ & $54.9 \%$ \\
\hline Worse than the US national benchmark & $7.0 \%$ & $8.2 \%$ & $5.5 \%$ & $6.6 \%$ & $7.0 \%$ & & $7.1 \%$ & $7.5 \%$ & $6.4 \%$ \\
\hline Number of cases too small & $1.2 \%$ & $0.0 \%$ & $3.3 \%$ & $1.0 \%$ & $5.2 \%$ & & $1.8 \%$ & $0.0 \%$ & $3.5 \%$ \\
\hline Not available & $22.1 \%$ & $29.1 \%$ & $19.9 \%$ & $25.8 \%$ & $34.3 \%$ & & $23.3 \%$ & $32.5 \%$ & $31.1 \%$ \\
\hline \multicolumn{10}{|c|}{ Rate of readmission after discharge from hospital (hospital-wide) } \\
\hline Better than the US national benchmark & $10.4 \%$ & $9.2 \%$ & $14.9 \%$ & $10.6 \%$ & $15.7 \%$ & * & $11.7 \%$ & $8.8 \%$ & $14.0 \%$ \\
\hline No different than the US national benchmark & $72.3 \%$ & $70.4 \%$ & $68.5 \%$ & $71.7 \%$ & $70.7 \%$ & & $70.9 \%$ & $73.8 \%$ & $69.8 \%$ \\
\hline Worse than the US national benchmark & $15.0 \%$ & $14.3 \%$ & $9.9 \%$ & $16.2 \%$ & $8.3 \%$ & & $12.8 \%$ & $11.3 \%$ & $12.8 \%$ \\
\hline Number of cases too small & $0.0 \%$ & $5.6 \%$ & $3.3 \%$ & $0.0 \%$ & $2.2 \%$ & & $2.4 \%$ & $5.0 \%$ & $1.5 \%$ \\
\hline Not available & $2.3 \%$ & $0.5 \%$ & $3.3 \%$ & $1.5 \%$ & $3.1 \%$ & & $2.4 \%$ & $1.3 \%$ & $2.0 \%$ \\
\hline
\end{tabular}

Chi-square test $\left.{ }^{*} p<0.05 ; * * 0.001\right)$

significant correlation between the scaled survey online ratings and the sentiment of the narrative comments $(\rho=0.797 ; p<0.001)$.

\section{Discussion}

This study determined the association between online ratings and clinical quality of care measures to assess the usefulness of the ratings for patients when searching for a hospital. In contrast to previous studies (see below), we collected an equal number of very positive, positive, neutral, negative and very negative online ratings to get a more in-depth knowledge of the association and distribution of the online ratings according to the clinical performance. Our results show that online ratings seem to have limited potential to guide patients to high-performing hospitals. Based on our analysis, relying on a very positive online rating was associated with a higher probability of selecting a high-performing hospital in only two of the nine nominally scaled measures. Furthermore, the probability of selecting such a hospital was greatest in very negative online ratings in two measures. We further present some modest associations between metrically scaled online ratings and clinical performance measures $(\rho= \pm 0.143$, $p<0.05$ for all). Therein, eight of the thirteen significant associations indicate better clinical outcomes for higher star ratings.

We could detect a significant association between the general rate of readmission after discharge from hospital $(\rho=-0.070, p<0.05)$ and the online ratings, which is in line with the results from two similar studies. First, the authors showed slightly stronger, but still weak and modest significant correlations between scaled survey online ratings for US hospitals from Yelp and three readmission related outcome measures (myocardial infarction, -0.17 ; heart failure, -0.31 ; pneumonia, -0.18 ) and two of three mortality outcome measures (myocardial infarction, - 0.19; pneumonia, - 0.14) [23]. Second, the study from the UK showed mixed but also slightly stronger results [37]. While positive online recommendations displayed on NHS Choices were significantly associated with lower hospital standardized mortality ratios $(\rho=-0.20 ; p=0.01)$, lower mortality from high-risk conditions $(\rho=-0.23 ; p=0.01)$, and lower readmission rates within 28 days $(\rho=-0.31 ; p<0.001)$, no association could be determined with mortality rates among surgical inpatients with serious treatable complications $(\rho=0.00 ; p=0.99)$ or mortality from low-risk conditions $(\rho=0.03 ; p=0.70)$. The results from those two studies indicate that better online ratings are associated with better clinical outcomes. Whether the fact that the authors used disease-specific performance metrics for their analysis might account for the stronger associations should be addressed in future research.

However, our results also indicate that better online ratings can be associated with lower clinical outcomes. One reason for this finding might be that the rating system of RateMDs does not explicitly cover certain aspects of clinical care or the quality of the care process. Looking at those clinical indicators for which a negative association with the online ratings could be determined, it becomes apparent that those are hardly covered by any of the RateMDs rating categories. For example, three 
Table 5 The association between online ratings and quality of care measures (Spearman rank coefficient of correlation)

\begin{tabular}{|c|c|c|c|c|c|c|}
\hline \multicolumn{2}{|c|}{ Clinical quality of care measures } & \multirow[t]{2}{*}{$\mathrm{N}$} & \multicolumn{2}{|c|}{$\begin{array}{l}\text { Adjusted association } \\
\text { with scaled survey } \\
\text { ratings }(p \text { value })^{\mathrm{a}}\end{array}$} & \multicolumn{2}{|c|}{$\begin{array}{l}\text { Adjusted association } \\
\text { with narrative comment } \\
\text { sentiment }(p \text { value })^{\mathrm{a}}\end{array}$} \\
\hline \multicolumn{6}{|c|}{ Healthcare Associated Infections } & \\
\hline 1 & HAI_1_SIR: Central Line-Associated Bloodstream Infection (CLABSI) & 829 & -0.087 & .012 & -0.061 & .080 \\
\hline 2 & HAI_2_SIR: Catheter-Associated Urinary Tract Infections (CAUTI) & 862 & 0.018 & .587 & 0.035 & .302 \\
\hline 3 & HAI_5_SIR: MRSA blood Laboratory-identified Events (bloodstream infections) & 748 & -0.017 & 648 & -0.027 & .463 \\
\hline 4 & HAI_6_SIR: C. diff. Laboratory identified Events (Intestinal infections) & 959 & -0.061 & .053 & 0.016 & .608 \\
\hline \multicolumn{7}{|c|}{ Readmissions Complications and Deaths } \\
\hline 5 & PSI_12_Score: Serious blood clots after surgery & 941 & 0.035 & .282 & 0.039 & .230 \\
\hline 6 & PSI_15_Score: Accidental cuts and tears from medical treatment & 937 & -0.008 & .799 & -0.005 & .871 \\
\hline 7 & PSI_6_Score: Collapsed lung due to medical treatment & 944 & 0.080 & .013 & 0.078 & .016 \\
\hline 8 & PSI_90_Score: Serious complications (summary measure; PSI-90-SAFETY) & 938 & 0.019 & .559 & 0.021 & .509 \\
\hline 9 & READM_30_Score: Rate of readmission after discharge from hospital & 982 & -0.070 & .015 & 0.011 & .700 \\
\hline \multicolumn{7}{|c|}{ Timely and Effective Care } \\
\hline 10 & $\begin{array}{l}\text { ED_1b: Average time patients spent in the emergency department, } \\
\text { before they were admitted to the hospital as an inpatient }\end{array}$ & 950 & -0.052 & .100 & -0.052 & .103 \\
\hline 11 & $\begin{array}{l}\text { ED_2b: Average time patients spent in the emergency department, } \\
\text { after the doctor decided to admit them as an inpatient before } \\
\text { leaving the emergency department for their inpatient room }\end{array}$ & 949 & -0.038 & .228 & -0.051 & .112 \\
\hline 12 & $\begin{array}{l}\text { OP_18b: Average time patients spent in the emergency department } \\
\text { before being sent home }\end{array}$ & 930 & -0.094 & .004 & -0.085 & .008 \\
\hline 13 & $\begin{array}{l}\text { OP_20: Average time patients spent in the emergency department } \\
\text { before they were seen by a healthcare professional }\end{array}$ & 928 & -0.090 & .005 & -0.113 & .000 \\
\hline 14 & $\begin{array}{l}\text { OP_22: Percentage of patients who left the emergency department } \\
\text { before being seen }\end{array}$ & 942 & -0.096 & .002 & -0.058 & .059 \\
\hline 15 & $\begin{array}{l}\text { OP_6: Outpatients having surgery who got an antibiotic at the right } \\
\text { time - within one hour before surgery }\end{array}$ & 927 & -0.083 & .009 & -0.034 & .284 \\
\hline 16 & OP_7: Outpatients having surgery who got the right kind of antibiotic & 927 & 0.061 & .056 & 0.041 & .201 \\
\hline 17 & $\begin{array}{l}\text { SCIP_CARD_2: Surgery patients who were taking heart drugs called } \\
\text { beta blockers before coming to the hospital, who were kept on the } \\
\text { beta blockers during the period just before and after their surgery }\end{array}$ & 971 & -0.010 & .738 & -0.059 & .053 \\
\hline 18 & $\begin{array}{l}\text { SCIP_INF_1: Surgery patients who were given an antibiotic at the } \\
\text { right time (within one hour before surgery) to help prevent infection }\end{array}$ & 979 & -0.066 & .026 & -0.026 & .380 \\
\hline 19 & $\begin{array}{l}\text { SCIP_INF_10: Patients having surgery who were actively warmed in } \\
\text { the operating room or whose body temperature was near normal } \\
\text { by the end of surgery }\end{array}$ & 984 & -0.065 & .027 & -0.079 & .007 \\
\hline 20 & $\begin{array}{l}\text { SCIP_INF_2: Surgery patients who were given the right kind of } \\
\text { antibiotic to help prevent infection }\end{array}$ & 979 & 0.049 & .099 & -0.023 & .429 \\
\hline 21 & $\begin{array}{l}\text { SCIP_INF_3: Surgery patients whose preventive antibiotics were } \\
\text { stopped at the right time (within } 24 \mathrm{~h} \text { after surgery) }\end{array}$ & 979 & -0.013 & 672 & -0.098 & .001 \\
\hline 22 & $\begin{array}{l}\text { SCIP_INF_9: Surgery patients whose urinary catheters were removed } \\
\text { on the first or second day after surgery. }\end{array}$ & 977 & 0.037 & .213 & -0.011 & .709 \\
\hline 23 & $\begin{array}{l}\text { SCIP_VTE_2: Patients who got treatment at the right time (within } \\
24 \mathrm{~h} \text { before or after their surgery) to help prevent blood clots after } \\
\text { certain types of surgery }\end{array}$ & 980 & -0.097 & .001 & -0.114 & .000 \\
\hline 24 & $\begin{array}{l}\text { VTE_1: Patients who got treatment to prevent blood clots on the } \\
\text { day of or day after hospital admission or surgery }\end{array}$ & 967 & 0.143 & .000 & 0.070 & .028 \\
\hline 25 & $\begin{array}{l}\text { VTE_2: Patients who got treatment to prevent blood clots on the } \\
\text { day of or day after being admitted to the intensive care unit (ICU) }\end{array}$ & 940 & 0.058 & .073 & 0.034 & .296 \\
\hline 26 & VTE_3: Patients with blood clots who got the recommended & 918 & 0.111 & .001 & 0.049 & .133 \\
\hline
\end{tabular}


Table 5 The association between online ratings and quality of care measures (Spearman rank coefficient of correlation) (Continued)

\begin{tabular}{|c|c|c|c|c|c|c|}
\hline \multicolumn{2}{|c|}{ Clinical quality of care measures } & \multirow{2}{*}{$\begin{array}{l}N \\
779\end{array}$} & \multicolumn{2}{|c|}{$\begin{array}{l}\text { Adjusted association } \\
\text { with scaled survey } \\
\text { ratings ( } p \text { value) })^{\mathrm{a}}\end{array}$} & \multicolumn{2}{|c|}{$\begin{array}{l}\text { Adjusted association } \\
\text { with narrative comment } \\
\text { sentiment ( } p \text { value })^{\mathrm{a}}\end{array}$} \\
\hline 27 & $\begin{array}{l}\text { VTE_4: Patients with blood clots who were treated with an } \\
\text { intravenous blood thinner, and then were checked to determine } \\
\text { if the blood thinner was putting the patient at an increased } \\
\text { risk of bleeding }\end{array}$ & & 0.009 & .797 & 0.001 & .991 \\
\hline 28 & $\begin{array}{l}\text { VTE_5: Patients with blood clots who were discharged on } \\
\text { a blood thinner medicine and received written instructions } \\
\text { about that medicine }\end{array}$ & 907 & 0.038 & .256 & 0.006 & .864 \\
\hline 29 & $\begin{array}{l}\text { VTE_6: Patients who developed a blood clot while in the } \\
\text { hospital who did not get treatment that could have prevented it }\end{array}$ & 602 & -0.117 & .007 & -0.054 & .187 \\
\hline
\end{tabular}

${ }^{a}$ Adjusted for Hospital Type, Hospital Ownership, and Emergency Service

Abbreviations: PSI: Patient Safety Indicators, ED: Emergency Department, OP: Outpatient, SCIP: Surgical Care Improvement Project, VTE: Venous Thromboembolism

negative associations were related to receiving care at the right time (e.g., outpatients having surgery who got an antibiotic at the right time-within one hour before surgery). It seems likely that patients might not be able to capture or be even aware of the time an antibiotic or similar treatment has to be given.

The evidence regarding the association between narrative comments and clinical performance measures is even more scarce. As shown above, relying on comments with a positive sentiment leads to a higher probability of choosing a well-performing hospital in five of the nine nominally scaled measures. However, this choice behavior would also increase the risk of choosing a low-performing hospital. Furthermore, only seven of the twenty-nine associations between the sentiment of the narrative comments and metrically scaled clinical outcomes could be shown to be statistically significant. Therein, three associations indicate better clinical outcomes in more favorable narrative comments whereas four measures indicate lower clinical performance scores in positive narrative comments. Consequently, it might be questionable whether their broader incorporation into report cards would be of use for patients [22]. Also interestingly, quality measures for which a significant association with the sentiment of the comments could be detected were all but one (i.e., surgery patients whose preventive antibiotics were stopped at the right timewithin $24 \mathrm{~h}$ after surgery)-the same indicators for which the quantitative ratings have also shown a significant association. In addition, all of them showed the same direction of association. Given the fact that users are also only able to process a limited amount of information at a time so as not to be overwhelmed with information [38], it seems reasonable to state that the information that contributes to better decisions (e.g., in terms of selecting a high-performing hospital) should be particularly presented [39]. Taken together, despite recent suggestions of incorporating narrative comments into report cards [14, 33, 40-42], their usefulness in the report card's current form might be limited for patients who search for a well performing hospital.

One possible reason for this might be the request posed for leaving a comment on the report card RateMDs which served as the basis for our analysis, which is as follows: "Please leave a comment with more detail about your experience." The fact that it does not seem to be very specific might account for the fact that more general comments were being left by the patients. It may be possible that narrative comments from other report cards lead to different findings, even though the posed requests there do not seem to be not much more specific, as the following examples demonstrate: "Your review: Your review helps others learn about great local businesses" (Yelp); "Write your review: Add a review" (beside it for a few seconds appears: "A good review is: both detailed and specific; Consider writing about: pros and cons, some things people might not know about the listing") (Find the Best - Health Grove); and "Write a Review" (Wellness). Whether or not narrative comments from those rating websites lead to different findings shall be addressed in future studies. In addition, research should also assess whether more specific requests would lead to comments which are more highly correlated with clinical performance metrics and thus might add value for patients when searching for a well performing hospital.

As mentioned above, a recent study from the Netherlands has shown that low online ratings might be used so that patients avoid low-performing hospitals [20]. More specifically, the authors have demonstrated that information from social media can be used to integrate patient's perspective in supervision and this information could be used from health care inspectorates to undertake risk-based supervision of elderly care. Based on this, we analyzed whether low online ratings from RateMDs might be helfpul for patients so as to avoid low-performing hospitals. When looking at the distribution of the one star scaled survey ratings on RateMDs, we could see similar percentages for low and high performing hospitals (Better than the US national benchmark: $8.7 \%$ vs. Worse than the US 
national benchmark: $8.3 \%$, respectively). Here, most hospitals can be assigned to the average performance group (No different than the US national benchmark: $59.5 \%)$. Based on those numbers, we conclude that low online ratings are of limited usefulness for patients when trying to avoid low-performing hospitals. However, further research should explore the usefulness of low online ratings more in detail.

There are some limitations that have to be taken into account when the results of this study are interpreted. First, our study adopted a cross-sectional design, so we were able to identify associations between exposure and outcomes but could not infer cause and effect. Second, our systematic search procedure was limited to the Medline database (via PubMed). We did not include further databases since it was not our primary aim to carry out a comprehensive and systematic literature review but to capture the literature in the most relevant database. However, we checked all references in the studies and also searched Google to capture relevant literature. Due to our different approach by incorporating an equal number of ratings among all rating scores, our results should be compared with caution with those from other studies. For example, it is not surprising that the percentage of narrative comments with a negative sentiment is larger in our study compared with previously published studies, since most ratings on report cards have been shown to be mostly positive (see above). Furthermore, since one purpose of this study was to address the differences of ratings among the five rating scores we did not create a representative sample of hospitals. Nevertheless, as shown above we calculated risk-adjusted result. In addition, it should be mentioned that we did not analyze the validity or reliability of the used quality indicators. Instead, we used those quality indicators that are being published on the report card Hospital Compare. As a further limitation, it has to be mentioned that our study determined the usefulness of online ratings for patients when searching for a hospital by assessing the association between online ratings and clinical quality of care measures. Nevertheless, research has demonstrated that patients might prefer other aspects of care when choosing a hospital [43]. The analysis of the association of such measures and online ratings might lead to different findings. Finally, our analysis is only based on online ratings from the US report card RateMDs. Thus, our findings cannot be generalized for online ratings on other US hospital rating websites or those from other countries. The analysis of ratings from other US websites might lead to other conclusions. In addition, it might be interesting to compare the narratives between report cards from different countries. Because of the major differences between the systems in the US and other countries, there might be also differences in the way patient rate and tell their story about hospitals.

\section{Conclusions}

In sum, whether patients who search for a well performing hospital in terms of clinical quality of care should rely on online ratings to make a choice can be answered in part. Based on our results, there seems to be some association between quantitative online ratings and clinical performance measures. Nevertheless, the relatively weak strength and inconsistency of the direction of the associations, as well as the lack of association with several other clinical measures, may not enable us to draw strong conclusions. For some measures, we even detected a negative association, which has the potential to mislead patients. Despite the promise of incorporating narrative comments into report cards to engage patients in their use, they seem to have limited potential to reflect the clinical quality of care in its current form. Only a small proportion of the tested associations was statistically significant; four out of the seven were even negatively associated with the sentiment of the comments. In addition, the indicators for which a significant association with the sentiment of the comments could be detected were almost all covered by indicators for which the quantitative ratings had shown a significant association. Whether or not the usefulness of narrative comments can be increased by posing more specific requests for leaving a narrative comment should be addressed in future studies.

\section{Additional file}

Additional file 1: Word document. Overview of the applied categorization scheme \& Codebook. (DOCX $42 \mathrm{~kb}$ )

\section{Abbreviations}

C. diff.: Clostridium difficile; CAUTI: Catheter-Associated Urinary Tract Infections; CLABSI: Central Line-Associated Bloodstream Infection; CMS: Centers for Medicare and Medicaid Services; MRSA: Methicillin-resistant Staphylococcus aureus; NHS: National Health Service; UK: United Kingdom; US: United States of America

\section{Acknowledgements}

None reported.

\section{Funding}

ME reports receiving support from a 2014/2015 Commonwealth Fund/ Robert Bosch Foundation Harkness Fellowship in Health Care Policy and Practice. The views presented here are those of the authors and should not be attributed to The Commonwealth Fund or its directors, officers, or staff.

\section{Availability of data and materials}

Data will be available by emailing martin.emmert@fau.de.

Authors' contributions

ME is the principal investigator of the study who designed the study and coordinated all aspects of the research including all steps of the manuscript preparation. He is responsible for the study concept, design, writing, reviewing, editing and approving the manuscript in its final form. NM and MS contributed in the study design, analysis and interpretation of data, drafting the work, writing the manuscript and reviewed and approved the manuscript. All authors read and approved the final manuscript. 


\section{Ethics approval and consent to participate}

For our analysis, we only used publicly available data from Hospital Compare and RateMDs.

\section{Consent for publication}

Not applicable

\section{Competing interests}

The authors declare that they have no competing interests.

\section{Publisher's Note}

Springer Nature remains neutral with regard to jurisdictional claims in published maps and institutional affiliations.

\section{Author details}

'2014-15 Harkness \& Robert Bosch Fellow in Healthcare Policy and Practice; Department of Health Policy and Management, Yale University, School of Public Health, 47 College Street, New Haven, CT 06520, USA.

${ }^{2}$ Friedrich-Alexander-University Erlangen-Nuremberg, School of Business and Economics, Institute of Management (IFM), Lange Gasse 20, 90403 Nuremberg, Germany. ${ }^{3}$ Chair of Health Care Management, Lange Gasse 20, 90403 Nuremberg, Germany. ${ }^{4}$ Yale University, School of Public Health, Room 304 LEPH, 60 College Street, New Haven, CT 06520, USA.

Received: 26 August 2016 Accepted: 23 January 2018 Published online: 05 February 2018

\section{References}

1. Emmert M, Meier F, Heider A-K, Dürr C, Sander U. What do patients say about their physicians? An analysis of 3000 narrative comments posted on a German physician rating website. Health Policy. 2014;118(1):66-73.

2. Gao GG, McCullough JS, Agarwal R, Jha AK. A changing landscape of physician quality reporting: analysis of patients' online ratings of their physicians over a 5-year period. J Med Internet Res. 2012;14(1):e38.

3. López A, Detz A, Ratanawongsa N, Sarkar U. What patients say about their doctors online: a qualitative content analysis. J Gen Intern Med. 2012:1-8.

4. Reimann S, Strech D. The representation of patient experience and satisfaction in physician rating sites. A criteria-based analysis of English-and German-language sites. BMC Health Serv Res. 2010;10(1):332.

5. Emmert M, Meier $F$. An analysis of online evaluations on a physician rating website: evidence from a German public reporting instrument. J Med Internet Res. 2013;15(8):e157.

6. Greaves F, Millett C. Consistently increasing numbers of online ratings of healthcare in England. J Med Internet Res. 2012;14(3):e94.

7. D. Strech, S. Reimann, Deutschsprachige Arztbewertungsportale: Der Status quo ihrer Bewertungskriterien, Bewertungstendenzen und Nutzung: German Language Physician Rating Sites: The Status Quo of Evaluation Criteria, Evaluation Tendencies and Utilization, Gesundheitswesen 74 (2012) e61-e67.

8. Emmert M, Meier F, Pisch F, Sander U. Physician choice making and characteristics associated with using physician-rating websites: crosssectional study. J Med Internet Res. 2013;15(8):e187.

9. Bakhsh W, Mesfin A. Online ratings of orthopedic surgeons: analysis of 2185 reviews. Am J Orthop. 2014;43(8):359-63.

10. Greaves F, Pape UJ, Lee H, Smith DM, Darzi A, Majeed A, Millett C. Patients' ratings of family physician practices on the internet: usage and associations with conventional measures of quality in the English National Health Service. J Med Internet Res. 2012;14(5):e146.

11. Kadry B, Chu L, Kadry B, Gammas D, Macario A. Analysis of 4999 online physician ratings indicates that most patients give physicians a favorable rating. J Med Internet Res. 2011;13(4):e95.

12. Lagu T, Hannon NS, Rothberg MB, Lindenauer PK. Patients' evaluations of health care providers in the era of social networking: an analysis of physician-rating websites. J Gen Intern Med. 2010;25(9):942-6.

13. Mackay B. RateMDs.com nets ire of Canadian physicians. Can Med Assoc J. 2007;176(6):754.

14. Greaves F, Millett C, Nuki P. England's experience incorporating "anecdotal" reports from consumers into their National Reporting System: lessons for the United States of what to do or not to do? Med Care Res Rev. 2014;71 (5 Suppl):65S-80S.
15. Emmert M, Sander U, Esslinger AS, Maryschok M, Schoeffski O. Public reporting in Germany: the content of physician rating websites. Methods Inf Med. 2012;51(2):112-20.

16. Emmert M, Sander U, Pisch F. Eight questions about physician-rating websites: a systematic review. J Med Internet Res. 2013;15(2):e24.

17. Verhoef LM, Van de Belt TH, Engelen LLLPG, Schoonhoven L, Kool RB. Social media and rating sites as tools to understanding quality of care: a scoping review. J Med Internet Res. 2014;16(2):e56.

18. Austin JM, Jha AK, Romano PS, Singer SJ, Vogus TJ, Wachter RM, Pronovost PJ. National hospital ratings systems share few common scores and may generate confusion instead of clarity. Health affairs (Project Hope). 2015;34(3):423-30.

19. Rothberg MB, Morsi E, Benjamin EM, Pekow PS, Lindenauer PK. Choosing the best hospital: the limitations of public quality reporting. Health affairs (Project Hope). 2008;27(6):1680-7.

20. van de Belt TH, Engelen LLLG, Verhoef $L M$, van der Weide MJA, Schoonhoven L, Kool RB. Using patient experiences on Dutch social media to supervise health care services: exploratory study. J Med Internet Res. 2015;17(1):e7.

21. de Barra M, Eriksson K, Strimling P. How feedback biases give ineffective medical treatments a good reputation. J Med Internet Res. 2014;16(8):e193.

22. Schlesinger M, Kanouse DE, Martino SC, Shaller D, Rybowski L. Complexity, public reporting, and choice of doctors: a look inside the blackest box of consumer behavior. Med Care Res Rev. 2014;71(5 Suppl):38S-64S.

23. Bardach NS, Asteria-Peñaloza R, Boscardin WJ, Dudley RA. The relationship between commercial website ratings and traditional hospital performance measures in the USA. BMJ Qual Saf. 2013;22(3):194-202.

24. Okike K, Peter-Bibb TK, Xie KC, Okike ON. Association between physician online rating and quality of care. J Med Internet Res. 2016;18(12):e324.

25. Segal J, Sacopulos M, Sheets V, Thurston I, Brooks K, Puccia R. Online doctor reviews: do they track surgeon volume, a proxy for quality of care? J Med Internet Res. 2012;14(2):e50.

26. Elo S, Kyngäs $\mathrm{H}$. The qualitative content analysis process. J Adv Nurs. 2008; 62(1):107-15.

27. Glaser BG. The constant comparative method of qualitative analysis. Soc Probl. 1965;12:436-45.

28. Hsieh H-F, Shannon SE. Three approaches to qualitative content analysis. Qual Health Res. 2005;15(9):1277-88.

29. Foss C, Hofoss D. Patients' voices on satisfaction: unheeded women and maltreated men? Scand J Caring Sci. 2004;18(3):273-80.

30. Greaves F, Ramirez-Cano D, Millett C, Darzi A, Donaldson L. Use of sentiment analysis for capturing patient experience from free-text comments posted online. J Med Internet Res. 2013;15(11):e239.

31. Santuzzi NR, Brodnik MS, Rinehart-Thompson L, Klatt M. Patient satisfaction: how do qualitative comments relate to quantitative scores on a satisfaction survey? Qual Manag Health Care. 2009;18(1):3-18.

32. Centers for Medicare \& Medicaid Services, Hospital Compare Downloadable Database Data Dictionary: System Requirements Specification, 2014.

33. Lagu T, Goff SL, Hannon NS, Shatz A, Lindenauer PK. A mixed-methods analysis of patient reviews of hospital care in England: implications for public reporting of health care quality data in the United States. Jt Comm J Qual Patient Saf. 2013;39(1):7-15.

34. Greaves F, Laverty AA, Cano DR, Moilanen K, Pulman S, Darzi A, Millett C. Tweets about hospital quality: a mixed methods study. BMJ Qual Saf. 2014;23(10):838-46

35. Lövgren G, Engström B, Norberg A. Patients' narratives concerning good and bad caring. Scand J Caring Sci. 1996;10(3):151-6.

36. Wong ELY, Coulter A, Cheung AWL, Yam CHK, Yeoh EK, Griffiths SM. Patient experiences with public hospital care: first benchmark survey in Hong Kong. Hong Kong Med J. 2012;18(5):371-80.

37. Greaves F, Pape UJ, King D, Darzi A, Majeed A, Wachter RM, Millett C. Associations between web-based patient ratings and objective measures of hospital quality. Arch Intern Med. 2012;172(5):435-6.

38. Slovic P. Towards understanding and improving decisions. In: Howell WC Fleishman EA, Hillsdale NJ, editors. Human performance and productivity. Information processing and decision making, 2nd ed. Hillsdale: Erlbaum; 1982. p. 157-83.

39. Damman OC, Hendriks M, Rademakers J, Delnoij DMJ, Groenewegen PP. How do healthcare consumers process and evaluate comparative healthcare information? A qualitative study using cognitive interviews. BMC Public Health. 2009;9:423. 
40. Hibbard JH, Peters E. Supporting informed consumer health care decisions: data presentation approaches that fa-cilitate the use of information in choice. Annu Rev Public Health. 2003;24:413-33.

41. Lagu T, Lindenauer PK. Putting the public back in public reporting of health care quality. JAMA. 2010;304(15):1711-2.

42. Shaffer VA, Owens J, Zikmund-Fisher BJ. The effect of patient narratives on information search in a web-based breast cancer decision aid: an eye-tracking study. J Med Internet Res. 2013;15(12)

43. S.M. Kleefstra, Hearing the patient's voice: the patient's perspective as outcome measure in monitoring the quality of hospital care, Amsterdam, the Netherlands, 2016.

Submit your next manuscript to BioMed Central and we will help you at every step:

- We accept pre-submission inquiries

- Our selector tool helps you to find the most relevant journal

- We provide round the clock customer support

- Convenient online submission

- Thorough peer review

- Inclusion in PubMed and all major indexing services

- Maximum visibility for your research

Submit your manuscript at www.biomedcentral.com/submit
Biomed Central 